\title{
Chemical behaviour of iron base substrates in liquid $\mathrm{Mg}-\mathrm{Zn}$ alloys
}

\author{
J.C. Viala, D. Pierre, F. Bosselet, M. Peronnet and J. Bouix \\ Laboratoire des Multimatériaux et Interfaces, UMR CNRS 5615, Université Lyon I, \\ 69622 Villeurbanne Cedex, France
}

\begin{abstract}
The chemical reactivity between solid iron base substrates and magnesium melts containing zinc has been investigated at $1000 \mathrm{~K}$. Characterization by OM, SEM and EPMA of the interfacial zones formed after $65 \mathrm{~h}$ heating in a magnesium melt with $7.7 \mathrm{wt} \%$ of zinc added revealed a strong bonding between the iron substrates and the light alloy. Indications were obtained for the occurrence of some dissolutionrecrystallization at the solid/liquid interface. A 8-10 $\mu \mathrm{m}$ thick $\alpha \mathrm{Fe}(\mathrm{Al}, \mathrm{Si})$ reaction layer was observed to have formed at the substrates surface but zinc was not detected in this reaction layer. Thermodynamic considerations based on chemical activities are developed to account for that a priori surprising chemical behaviour.
\end{abstract}

\section{INTRODUCTION}

Light magnesium alloys $\left(\rho=1.7-1.9 \mathrm{~g} . \mathrm{cm}^{-3}\right)$ are more and more extensively employed to fabricate low-weight castings for transport vehicles [1]. Traditionally, melting of these alloys is carried out at temperatures equal to or slightly lower than $1000 \mathrm{~K}$, using iron or steel tools [2]. The reasons are that : (i) no chemical compound can form between iron and pure magnesium and (ii), the mutual solubilities between the two metals are very limited [2,3].

The excellent chemical inertness of solid iron towards pure liquid magnesium can however be strongly affected by the addition to the melt of alloying elements, specially those elements that can react with iron to give solid solutions with wide homogeneity range, such as $\mathrm{Al}, \mathrm{Si}$ [4-6], $\mathrm{Mn}$ [7], or intermetallic compounds, such as $\mathrm{Zr}$ [8]. For safety reasons as well as to reduce production cost, it is important to acquire a thorough understanding of the interface chemical reactions that can result from such additions. The present work deals with the effect of zinc addition. On the one hand, this element is effectively present in many magnesium casting alloys (generally in combination with aluminium or zirconium) at a concentration level ranging from 0.5 to $5 \mathrm{wt} \%(0,19$ to 1.9 at\% $[1,2]$. On the other hand, pure zinc in the liquid state is known to react very rapidly with iron $[9,10]$.

\section{EXPERIMENTAL}

To investigate interface reactions with binary liquid $\mathrm{Mg}-\mathrm{Zn}$ alloys, iron base substrates made of three different materials were used: pure iron, E24 mild steel and GS52 ferritic spheroidal graphite cast iron (Table 1). Small pieces $(1 \mathrm{~mm} \times 1 \mathrm{~mm} \times 2 \mathrm{~mm})$ of these materials were dry-polished on all their faces to a $3 \mu \mathrm{m}$ finish and cold-pressed under $240 \mathrm{MPa}$ with a synthetic $\mathrm{Mg}-\mathrm{Zn}$ alloy powder into parallelepipedic rods $(6 \mathrm{~mm} \times 6 \mathrm{~mm} \times 30 \mathrm{~mm}$, substrate:alloy weight ratio about 0.007$)$. The zinc content in the alloy powder was fixed at $7.7 \mathrm{wt} \%$ ( 3 at\%), a value voluntarily higher than the amount generally present in commercial alloys. The alloy powder also contained little amounts of foreign elements which were impurities of the starting magnesium powder (Table 1).

The cold-pressed rods were heated at $1000 \pm 3 \mathrm{~K}$ for $65 \mathrm{~h}$ under an atmospheric pressure of argon. Owing to an optimized layout of the sample in the hot-zone of the reaction tube, the weight loss could be reduced to less than $2 \%$. After rapid cooling, the samples were sawn and polished to a finish better than $1 \mu \mathrm{m}$. Transverse sections of the substrate/alloy interface were examined by optical microscopy (OM) and scanning electron microscopy (SEM). Concentration profiles of the elements 
at the crossing of the interface were also established point by point by electron probe microanalysis (EPMA), using a Cameca Camebax apparatus (CT $\mu$, Université Lyon 1, France).

Table 1 : Chemical composition of the starting materials, in $w t \%$. The values reported are those given by the supplier, except for Mg powder (Merck) which was analysed at the Service Central d'Analyse du CNRS (Vernaison, France)

\begin{tabular}{lllllllll}
\hline Material & $\mathrm{Al}$ & $\mathrm{C}$ & $\mathrm{Fe}$ & $\mathrm{Mn}$ & $\mathrm{P}$ & $\mathrm{S}$ & $\mathrm{Si}$ & $\mathrm{Zn}$ \\
\hline Pure iron (Goodfellow) & - & $<0.08$ & 99.5 & 0.3 & $<0.04$ & $<0.05$ & 0.1 & - \\
E24 mild steel (Sollac) & $<0.01$ & $<0.17$ & $>98.5$ & $<1.1$ & $<0.03$ & $<0.025$ & $<0.03$ & - \\
GS52 cast iron (Renault) & - & 3.80 & 92.4 & 0.35 & $<0.03$ & $<0.02$ & 3.30 & - \\
Mg powder (Merck) & $<0.02$ & - & $<0.05$ & 0.009 & - & - & 0.03 & $<0.05$ \\
\hline
\end{tabular}

\section{RESULTS}

It can be seen in Fig. 1 that after heating at $1000 \mathrm{~K}$ for $65 \mathrm{~h}$, a very intimate contact has been established between the substrates and the $\mathrm{Mg}$ - $\mathrm{Zn}$ alloy, without crack formation upon freezing and subsequent cooling. Another feature characterizing the substrate/alloy interfaces is the increase in roughness of the substrate surface. Effectively, this roughness which was less than $3 \mu \mathrm{m}$ before immersion has increased to 3-5 $\mu \mathrm{m}$ for pure iron, to $4-10 \mu \mathrm{m}$ for mild steel and up to $15 \mu \mathrm{m}$ for cast iron. In the latter case, graphite spheroids which were completely embedded in the cast iron substrate at the beginning of the heat-treatment are found protruding in the $\mathrm{Mg}-\mathrm{Zn}$ alloy at the end of that treatment. This clearly shows that some dissolution-recrystallization has occurred at the substrate/melt interface, although the solubility of iron in liquid magnesium is very low : of the order of $0.04 \mathrm{wt} \%$ at $1000 \mathrm{~K}$ [3].

EPMA analyses revealed the formation of a 8-10 $\mu \mathrm{m}$ thick transition layer at the substrates surface during the heat-treatment. The typical concentration profiles reported in Fig. 2 show that this transition layer consists of a Fe-rich $\alpha \mathrm{Fe}(\mathrm{Al}, \mathrm{Si})$ solid solution. For the E24 mild steel substrate, the maximum aluminium and silicon contents are of $2 \mathrm{wt} \%(3.8 \mathrm{at} \%)$ and $1.6 \mathrm{wt} \%$ ( 3 at\%), respectively. These two foreign elements are impurities of the magnesium melt (Table 1). As to zinc, it was found in the magnesium matrix but contrary to expectation, this element was not detectable in the transition layers. In fact, these layers were exactly of the same type as those formed under the same conditions in a zinc-free magnesium melt [5]. It thus appears that addition of $7.7 \mathrm{wt} \%$ of zinc to a magnesium melt has practically no effect on the reactivity at $1000 \mathrm{~K}$ of this melt towards iron base substrates.
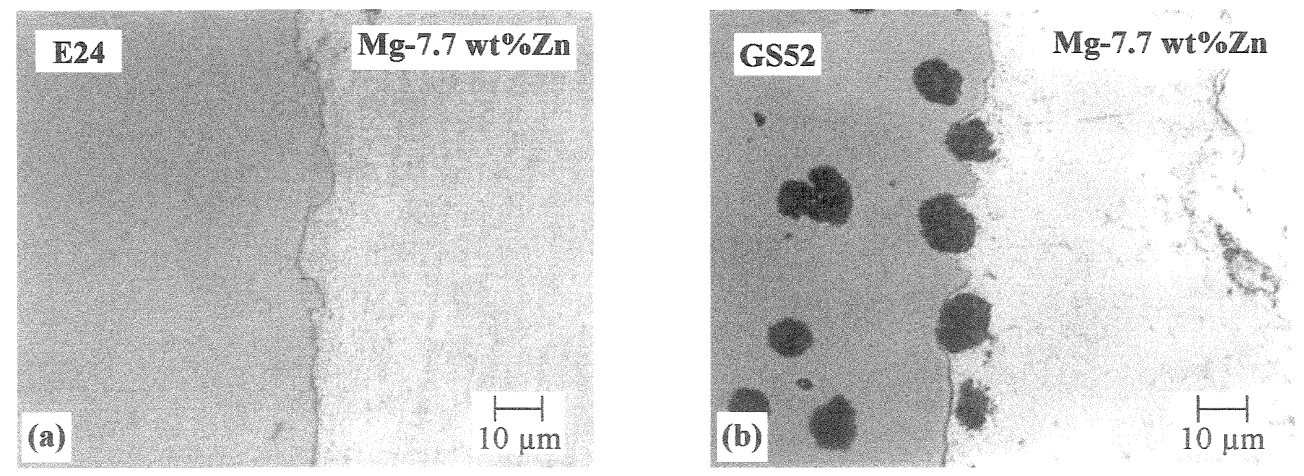

Figure 1 : Optical micrographs of the interface between iron base substrates and a $\mathrm{Mg}-\mathrm{Zn}$ alloy $(7.7 \mathrm{wt} \% \mathrm{Zn})$ after $65 \mathrm{~h}$ heating at $1000 \mathrm{~K}$ : (a) E24 mild steel; (b) GS52 spheroidal graphite cast iron. 

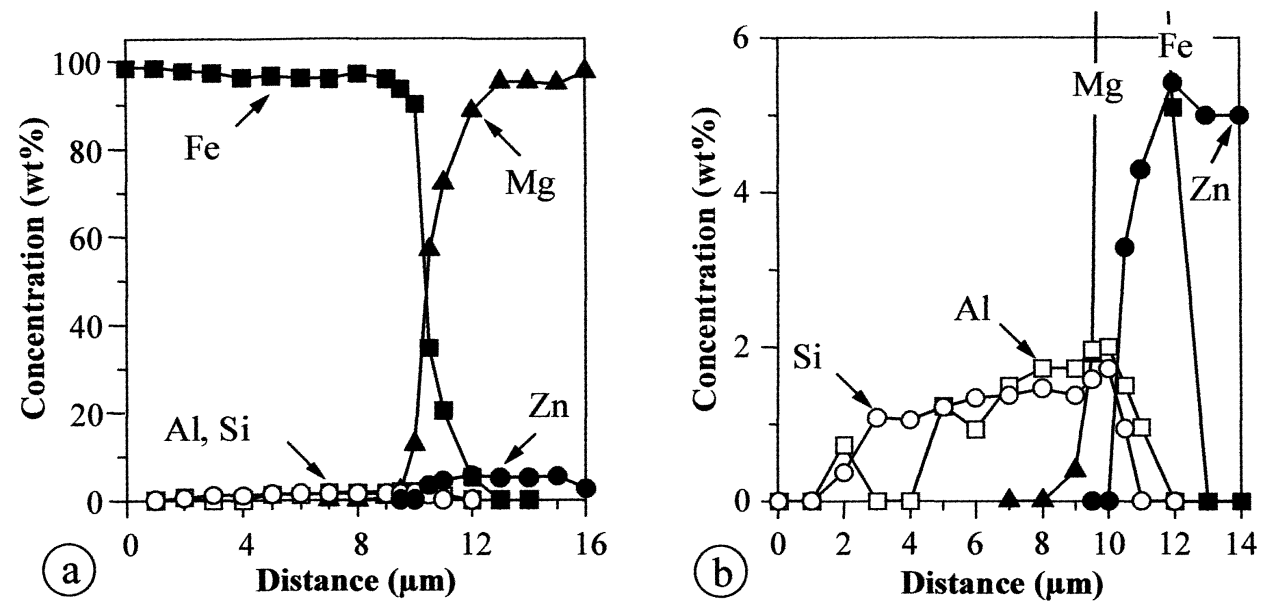

Figure 2 : EPMA concentration profiles for $\mathrm{Al}, \mathrm{Fe}, \mathrm{Mg}, \mathrm{Si}$ and $\mathrm{Zn}$ at the crossing of a E24/Mg- $\mathrm{Zn}(7.7 \mathrm{wt} \% \mathrm{Zn})$ interface after $65 \mathrm{~h}$ heating at $1000 \mathrm{~K}$ : (a) general view; (b) detailed view.

\section{DISCUSSION}

By comparison with other alloying elements that readily react with iron when present in liquid magnesium at levels as low as less than 500 wt-ppm for Al or Si [4-6] and less than $1 \mathrm{wt} \%$ for $\mathrm{Mn}$ [7] or $\mathrm{Zr}$ [8], it could a priori be thought that addition of $7.7 \mathrm{wt} \%$ of zinc (3 at\%) to a magnesium melt would have promoted a strong interfacial reaction with solid iron. Zinc can effectively form with iron a $\alpha \mathrm{Fe}$ solid solution with a homogeneity range extending at $1000 \mathrm{~K}$ up to $38.7 \mathrm{wt} \%$ of zinc (35 at\%) [3]. Moreover, a stable binary Fe-Zn compound $\Gamma$ containing 74.6-77.4 wt\% of zinc (71.574.5 at $\%)$ exists at this temperature $[3,9,10]$.

Contrary to expectation, such a strong interfacial reaction between dissolved zinc and iron is not observed. The question is then to explain this surprising inertness and to know if the reasons for it are of thermodynamic or kinetic order. In fact, these reasons have effectively their grounds in the thermodynamics of the Fe-Mg-Zn ternary system, but the foregoing qualitative considerations are too simplistic. To bring up a clear explanation of the observed behaviour, the following quantitative considerations have to be made.

Refined chemical activity data on the $\mathrm{Mg}-\mathrm{Zn}$ liquid phase have been recently reported at $933 \mathrm{~K}$ [11]. After a classical transformation (RTln $\gamma=k$ ) and a change in the reference state ( $\alpha \mathrm{Zn}$ with the A2 structure), values of chemical activity of zinc at $1000 \mathrm{~K}$ in a $\mathrm{Mg}-\mathrm{Zn}$ liquid have been derived and plotted in Fig. 3a. The same transformation has been applied to another set of chemical activity data reported for the Fe- $\mathrm{Zn}$ system at $930 \mathrm{~K}$ [12]. The values have also been plotted in Fig. 3a. It is clear from the activity-concentration curves drawn that the $\mathrm{Fe}-\mathrm{Zn}$ binary system is characterized by repulsive interactions in the solid state (positive deviation from Raoult's law) whereas attractive interactions obviously exist in the $\mathrm{Mg}$ - $\mathrm{Zn}$ binary liquid phase (large negative deviation from Raoult's law) [13]. Combination of these attractive and repulsive interactions give rise to the tie lines drawn in the Fe-Mg-Zn isothermal section shown in Fig. 3b.

It can be seen on the latter figure that a Mg-Zn liquid phase must contain at least $92.5 \mathrm{wt} \%$ (82 at\%) of zinc to be in equilibrium at $1000 \mathrm{~K}$ with the $\Gamma$ compound. For zinc contents lower than that value, the $\mathrm{Mg}-\mathrm{Zn}$ liquid phase is in equilibrium with different compositions of the $\alpha \mathrm{Fe}(\mathrm{Zn})$ solid solution. However, the tie lines rapidly join quasi-pure iron. As a consequence, the $\mathrm{Mg}-\mathrm{Zn}$ liquid containing $7.7 \mathrm{wt} \%$ of zinc (3 at\%) is in equilibrium with a $\alpha \mathrm{Fe}(\mathrm{Zn})$ solid solution containing only $0.035 \mathrm{wt} \%$ of zinc $(0.03 \mathrm{at} \%)$. Such a low zinc content in iron is of the order of the detection limit for the analytical technique used. This explains why zinc has not been detected at the surface of the iron base substrates after immersion for $65 \mathrm{~h}$ at $1000 \mathrm{~K}$ in such a liquid alloy. 

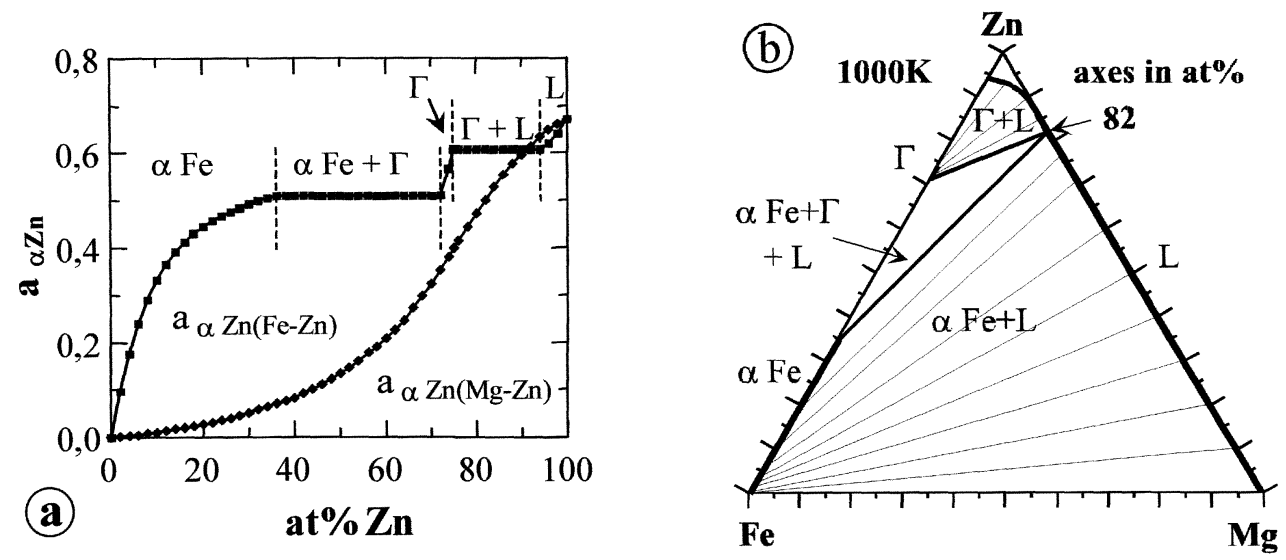

Figure 3 : (a) activity-concentration curves at $1000 \mathrm{~K}$ for zinc (reference state $\mathrm{A} 2$ ) in liquid $\mathrm{Mg}$ - $\mathrm{Zn}$ and solid $\mathrm{Fe}-\mathrm{Zn}$ binary mixtures; (b) corresponding tie lines at $1000 \mathrm{~K}$ in the $\mathrm{Fe}-\mathrm{Mg}-\mathrm{Zn}$ ternary system.

\section{CONCLUSION}

The aim of this work was to get a better insight into the chemical reactivity of magnesium melts containing zinc towards solid iron base tools. From the experimental results, it can be concluded that addition of up to $7.7 \mathrm{wt} \%$ of zinc to a magnesium melt has practically no effect on the reactivity at $1000 \mathrm{~K}$ of this melt towards iron base tools. Compared with aluminium and silicon which readily react with iron even though present in the melt as impurity traces (less than $500 \mathrm{wt}-\mathrm{ppm}$ ), the chemical inertness of zinc dissolved as major addition element might at first sight appear surprising. In fact, thermodynamic considerations based on chemical activities account for that inertness which results from the combination of $\mathrm{Fe}-\mathrm{Zn}$ repulsive interactions in the solid state with $\mathrm{Mg}-\mathrm{Zn}$ attractive interactions in the liquid phase.

\section{References}

1. B.L. Mordike and K.U. Kainer, Magnesium Alloys and Their Applications (Wiley, Weinheim, 1998).

2. C.S. Roberts, Magnesium and Its Alloys (Wiley, New York, 1960).

3. T.B. Massalski, Binary Alloy Phase Diagrams (Am. Soc. for Metals, Metals Park, Ohio, 1986).

4. D. Pierre, Thèse de Doctorat, Université de Lyon, France (1999).

5. J.C. Viala, D. Pierre, F. Bosselet, M. Peronnet and J. Bouix, Scr. Mater. 40, 1185 (1999).

6. D. Pierre, M. Peronnet, F. Bosselet, J.C. Viala and J. Bouix, Mater Sci. Eng. B94, 186 (2002).

7. D. Pierre, J.C. Viala, M. Peronnet, F. Bosselet and J. Bouix, Mater. Sci. Eng.A under press.

8. D. Pierre, F. Bosselet, M. Peronnet, J.C. Viala and J. Bouix, Acta Mater. 49, 653 (2001).

9. A.R. Marder, Progress in Materials Science 40, 191 (2000).

10. M. Bretez, Thèse de Doctorat, , Université de Lille, France (1986).

11. Y.B. Kim, F. Sommer and B. Predel, J. Alloys and Compounds 247, 43 (1997).

12. M. Vangheluwe, Thèse de Doctorat, Université de Lille, France (1995).

13. A. Prince, Alloy Phase Equilibria, (Elsevier, Amsterdam, 1966), p. 20. 